\title{
Dynorphin Immunocytochemistry in the Rat Central Nervous System
}

\author{
HENRY KHACHATURIAN, STANLEY J. WATSON, ${ }^{1}$ MICHAEL E. LEWIS, \\ DAVID COY,${ }^{*}$ AVRAM GOLDSTEIN.†AND HUDA AKIL \\ Mental Health Research Institute, University of Michigan, Ann Arbor, MI 48109 \\ *Department of Medicine. Tulane University School of Medicine, New Orleans, LA 70195 and \\ $\dagger$ Addiction Research Foundation, Stanford University, Palo Alto, CA 94394
}

Received 16 August 1982

\begin{abstract}
KHACHATURIAN, H., S. J. WATSON, M. E. LEWIS, D. COY, A. GOLDSTEIN AND H. AKIL. Dynorphin immunocytochemistry in the rat central nervous system. PEPTIDES 3(6) 941-954, 1982.-The distribution of dynorphin in the central nervous system was investigated in rats pretreated with relatively high doses $(300-400 \mu \mathrm{g})$ of colchicine administered intracerebroventricularly. To circumvent the problems of antibody cross-reactivity, antisera were generated against different portions as well as the full dynorphin molecule (i.e., residues 1-13, 7-17, or 1-17). For comparison, antisera to [Leu]enkephalin (residues 1-5) were also utilized. Dynorphin was found to be widely distributed throughout the neuraxis. Immunoreactive neuronal perikarya exist in hypothalamic magnocellular nuclei, periaqueductal gray, scattered reticular formation sites, and other brain stem nuclei, as well as in spinal cord. Additionally, dynorphin-positive fibers or terminals occur in the cerebral cortex, olfactory bulb, nucleus accumbens, caudate-putamen, globus pallidus, hypothalamus, substantia nigra, periaqueductal gray, many brain stem sties, and the spinal cord. In many areas studied, dynorphin and enkephalin appeared to form parallel but probably separate anatomical systems. The results suggest that dynorphin occurs in neuronal systems that are immunocytochemically distinct from those containing other opioid peptides.
\end{abstract}

Dynorphin Immunocytochemistry Colchicine Antibody cross-reactivity Central nervous system

DYNORPHIN is an opioid peptide originally extracted and purified from porcine pituitary [24]. The incomplete sequence, dynorphin-(1-13), contains [Leu]enkephalin at residues $1-5$ at the $\mathrm{NH}_{2}$-terminus, but is much more potent in the guinea pig ileum myenteric plexus-longitudinal muscle bioassay. The entire amino acid sequence of the heptadecapeptide dynorphin is now known $[22,69]$. This sequence is not found in the beta-endorphin precursor, proopiomelanocortin [48] or the enkephalin precursor $[11,26$, 50], indicating that dynorphin arises from a separate biosynthetic route. The biosynthetic source of dynorphin is the recently sequenced beta-neo-endorphin/dynorphin precursor [35]. The anatomical distribution of dynorphin also differs from that of beta-endorphin and the enkephalins. Radioimmunoassay studies reveal a wide distribution of immunoreactive dynorphin in brain, with highest levels in hypothalamus, followed in descending order by pons-medulla and midbrain, hippocampus, striatum, cerebral cortex and cerebellum [23]. Immunohistochemical studies of dynorphin have shown its localization to be different from betaendorphin [78]. Dynorphin immunoreactivity was localized in posterior pituitary and the magnocellular (supraoptic and paraventricular) nuclei of the hypothalamus. Dynorphinpositive magnocellular perikarya were also found to contain vasopressin immunoreactivity and could be distinguished anatomically from enkephalin-positive parvocellular peri- karya in the paraventricular nucleus [77]. Thus, opioid peptide precursor and immunohistochemical studies independently provide clear evidence for the separateness of betaendorphin, enkephalin and dynorphin systems in brain.

Although immunocytochemical studies have provided detailed information on the localization in brain of betaendorphin $[5,6,7,17,49,66,75,79,80,82,83,89]$ and the enkephalins $[15,18,29,30,31,34,45,55,60,62,64,71,72$, $74,81]$, such studies of dynorphin distribution have not clearly revealed immunoreactivity in regions shown to have material detected by radioimmunoassay $[23,32,47]$. We have found that intracerebroventricular pretreatment of rats with very high doses of colchicine permits the visualization of previously undetected immunoreactive enkephalin systems in rat brain (Khachaturian et al., J. Neurosci., in press). In the present study, such colchicine pretreatments enabled the visualization of widespread extrahypothalamic systems of immunoreactive dynorphin neurons which in many cases have a parallel distribution with the enkephalins. Using antisera to various segments (i.e., $1-13,7-17$ ) or the full dynorphin molecule, we have been able to distinguish between dynorphin-like immunoreactivity and enkephalin-like immunoreactivity in the brain and spinal cord. The preliminary results of our findings have been reported elsewhere [84]. The focus of this paper, however, will be on dynorphin distribution in the central nervous system with some em-

\footnotetext{
'Requests for reprints should be addressed to Stanley J. Watson, Mental Health Research Institute, University of Michigan, Ann Arbor, MI 48109, (313) 763-3725.
} 
TABLE 1

LIST OF ANTISERA

\begin{tabular}{|c|c|c|c|}
\hline Antibody & Source & Specificity & Key Cross Reactivities \\
\hline \multirow{3}{*}{ Dynorphin: $\begin{array}{r}1-17 \\
1-13 \\
7-17\end{array}$} & Goldstein & $\mathrm{COOH}$-terminus & No known peptides \\
\hline & Goldstein & Dynorphin-(6-13) & No known peptides \\
\hline & $\begin{array}{l}\text { Watson and } \\
\text { Akil }\end{array}$ & $\mathrm{COOH}$-terminus & No known peptides \\
\hline $\begin{array}{l}\text { [Leu]enkephalin } \\
\text { (affinity purified) }\end{array}$ & $\begin{array}{l}\text { Watson and } \\
\text { Akil }\end{array}$ & $\mathrm{COOH}$-terminus & $\begin{array}{l}<6 \% \text { with [Met] } \\
\text { enkephalin }\end{array}$ \\
\hline Serotonin & $\begin{array}{l}\text { Watson and } \\
\text { Akil }\end{array}$ & & $\begin{array}{l}\text { No other known } \\
\text { indolamine or } \\
\text { catecholamine }\end{array}$ \\
\hline $\begin{array}{l}\text { Tyrosine } \\
\text { Hydroxylase }\end{array}$ & T. Joh & & Not tested \\
\hline
\end{tabular}

phasis on its separateness from the enkephalins in selected brain regions.

\section{METHOD}

Adult, male Sprague-Dawley rats were treated with varying amounts of colchicine $(50-400 \mu \mathrm{g}$ in $10 \mu \mathrm{l} 0.9 \% \mathrm{NaCl})$ injected stereotaxically into the right lateral ventricle (Khachaturian et al., J. Neurosci., in press). After 24 or 48 hours, each rat was anesthetized with sodium pentobarbital and perfused through the aorta with $50 \mathrm{ml}$ of ice cold $0.9 \%$ saline followed by ice cold $0.1 \mathrm{M}$ phosphate-buffered $4 \%$ formaldehyde ( $\mathrm{pH} \mathrm{7.4)}$ at $140 \mathrm{~mm} \mathrm{Hg}$ for 30 minutes. The brains were removed, blocked, stored overnight in phosphatebuffered $15 \%$ sucrose at $4^{\circ} \mathrm{C}$, and then frozen in isopentane at $-40^{\circ} \mathrm{C}$. Frontal and parasagittal sections of $20 \mu \mathrm{m}$ thickness were cut in a cryostat at $-20^{\circ} \mathrm{C}$, thaw-mounted onto subbed slides, and stored at $-70^{\circ} \mathrm{C}$.

For peroxidase-antiperoxidase immunocytochemistry [83], the tissues were air-dried and then incubated at $37^{\circ} \mathrm{C}$ with normal goat serum (GIBCO) at 1/30 dilution for 5-10 minutes. Primary rabbit antisera to specific peptides (Table 1) were diluted with $0.02 \mathrm{M}$ phosphate-buffered saline (PBS) and $0.3 \%$ Triton X-100 and incubated for 1 hour at $37^{\circ} \mathrm{C}$, and overnight at $4^{\circ} \mathrm{C}$ (approximately 24 hours). To ensure antibody specificity, some sections were incubated with antisera preadsorbed with excess peptide $(25-50 \mu \mathrm{M})$ against which the antiserum was raised, as well as preadsorbed with other peptides with amino acid sequences in common with the original peptide (eg., dynorphin antiserum preadsorbed with [Leu]enkephalin). The next day, the sections were washed in PBS ( $3 \times 10$ minutes), incubated for 5-10 minutes at $37^{\circ} \mathrm{C}$ with normal goat serum, and then with goat antirabbit serum (Sternberger-Meyer) at 1/100 dilution for 30 minutes, and at $4^{\circ} \mathrm{C}$ overnight. On the third day, the tissues were washed in PBS, incubated for 5-10 minutes at $37^{\circ} \mathrm{C}$ with normal goat serum followed by anti-horseradish peroxidase (anti-HRP) serum at 1/200 dilution for 40 minutes, washed in PBS, and incubated with $4 \mu \mathrm{g} / \mathrm{ml}$ HRP enzyme (Sigma, Type VI), for 40 minutes. To initiate the peroxidase reaction, the slide-mounted sections were immersed in a solution of $0.03 \% \mathrm{H}_{2} \mathrm{O}_{2}$ and $0.125 \mathrm{mg} / \mathrm{ml}$ diaminobenzidine (Sigma) for 15 minutes with constant stirring. The reacted sections were washed $(3 \times 10$ minutes $)$ in distilled water, briefly osmicated $\left(2 \% \mathrm{OsO}_{4}\right)$, washed, dyhydrated and mounted with Permount. Observations and photography were performed utilizing a Leitz Orthoplan microscope.

Several antisera to various portions of the dynorphin molecule were used in this study (Table 1). Dynorphin-(1-13) and dynorphin-17 were purchased from Peninsula Laboratories (San Carlos, CA) and dynorphin-(7-17) was synthesized in our laboratories. For comparative purposes we also employed antisera generated against [Leu]enkephalin, serotonin and tyrosine hydroxylase (from Dr. T. Joh, Cornell University). Certain antisera were purified using an affinity chromatography column with the peptide covalently linked to cyanogen bromide-activated Sepharose-4B [44]. This purification process increases the concentration of specific IgG molecules, resulting in an improved signal against a reduced background [76].

\section{RESULTS}

Dynorphin immunoreactivity is localized to perikarya and processes of neurons in many regions of the central nervous system (see Fig. 1). We have noted dynorphinimmunoreactive perikarya in telencephalic structures such as the cerebral cortex, hippocampus and amygdala, in hypothalamic magnocellular neurons, in mesencephalic periaqueductal central gray and reticular formation, in pontine and medullary reticular neurons including certain sensory and motor nuclei, and also in the spinal cord. We have also observed dynorphin-immunoreactive processes and terminals in all the above areas and additionally in the olfactory bulb, nucleus accumbens, caudate-putamen, globus pallidus, preoptic area, hippocampal mossy fibers, substantia nigra, many areas of the reticular formation including certain monoamine-containing nuclei, as well as in the spinal cord. The immunoreactive signal obtained using antisera against either dynorphin-(1-13) or dynorphin-17 (Fig. 4A, B, and $C, D$ ) was blocked by both of these peptides but not by [Leu]enkephalin, [Met]enkephalin, enkephalin-Arg ${ }^{6}-$ Gly $^{7}$. Leu $^{8}$, enkephalin-Arg ${ }^{6}-P_{1}{ }^{7}$, BAM-22P, peptide E, dynorphin-B, $\alpha$-neo-endorphin, or $\beta$-endorphin.

In the telencephalon, dynorphin-positive terminals are localized to some but not all olfactory bulb glomeruli (Fig. 2A). Here, immunoreactive fibers appear to originate in the olfactory nerve and innervate specific glomeruli. We have so far 


\section{DYNORPHIN}

A. APERIKARYA

FIBERS-TERMINALS

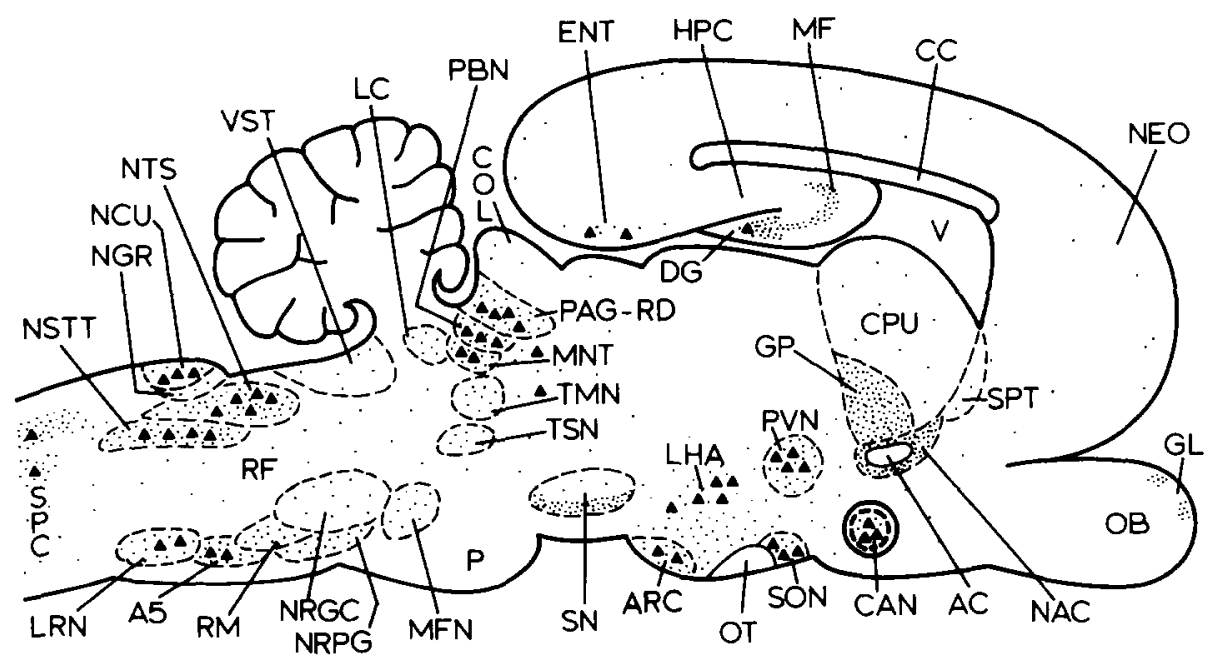

A5 noradrenergic nucleus A5

AC Anterior commissure

ARC Arcuate nucleus

CAN Central amygdaloid nucleus (projected)

CC Corpus callosum

COL Colliculi

CPU Caudate-putamen

DG Dentate gyrus

ENT Entorhinal cortex

GL Glomerular layer

GP Globus pallidus

HPC Hippocampus

LC Locus coeruleus

LHA Lateral hypothalamic area

LRN Lateral reticular nucleus

MF Mossy fibers

MFN Motor facial nucleus

MNT Mesencephalic nucleus of trigeminal

NAC Nucleus accumbens

NCU Nucleus cuneatus

NEO Neocortex

NGR Nucleus gracilis
NRGC Nucleus reticularis gigantocellularis

NRPG Nucleus reticularis paragigantocellularis

NSTT Nucleus of spinal tract of trigeminal

NTS Nucleus tractus solitarius

OB Olfactory bulb

OT Optic tract

$P \quad$ Pons

PAG Periaqueductal gray

PBN Parabrachial nucleus

PVN Paraventricular nucleus

RD Raphe dorsalis

RF Reticular formation

RM Raphe magnus

SN Substantia nigra

SON Supraoptic nucleus

SPC Spinal cord

SPT Septum

TMN Trigeminal motor nucleus

TSN Trigeminal sensory nucleus (Main)

V Ventricle

VST Vestibular nuclear complex

FIG. 1. A schematic summary of dynorphin distribution in the rat central nervous system, shown in parasagittal view (see text for details). Neuronal perikarya are represented by solid triangles, while fibers and terminals are shown as dots.

been unable to detect dynorphin-positive perikarya in the olfactory bulb or nerve. Diffuse, as well as punctate, dynorphin-like immunoreactivity is seen in the nucleus accumbens, caudate-putamen, globus pallidus, and preoptic area. Several regions of the cerebral cortex exhibit dynorphin-positive axonal processes including the frontal (Fig. 2B), parietal, cingulate, piriform, and entorhinal cortical areas. These fibers were frequently seen to traverse cortical layers I, II and III. Varicose immunoreactive processes were also noted in the lateral septum. In the amygdala, the central nucleus contains scattered small dynorphin-positive perikarya and fine varicose fibers (Fig. $3 \mathrm{~A}$ ). We have also noted scattered varicose fibers in the medial, lateral, cortical and basal amygdaloid nuclei. In the entorhinal cortex, a few small immunoreactive perikarya are distributed in layer II with distinct apical dendrites situated toward the surface and fine slender axons coursing into deeper layers (Fig 3B). Thus far, we have been able to detect only a few immunoreactive fibers in the perforant path linking the entorhinal cortex to the dentate gyrus. Within the hippocampal formation, a few 

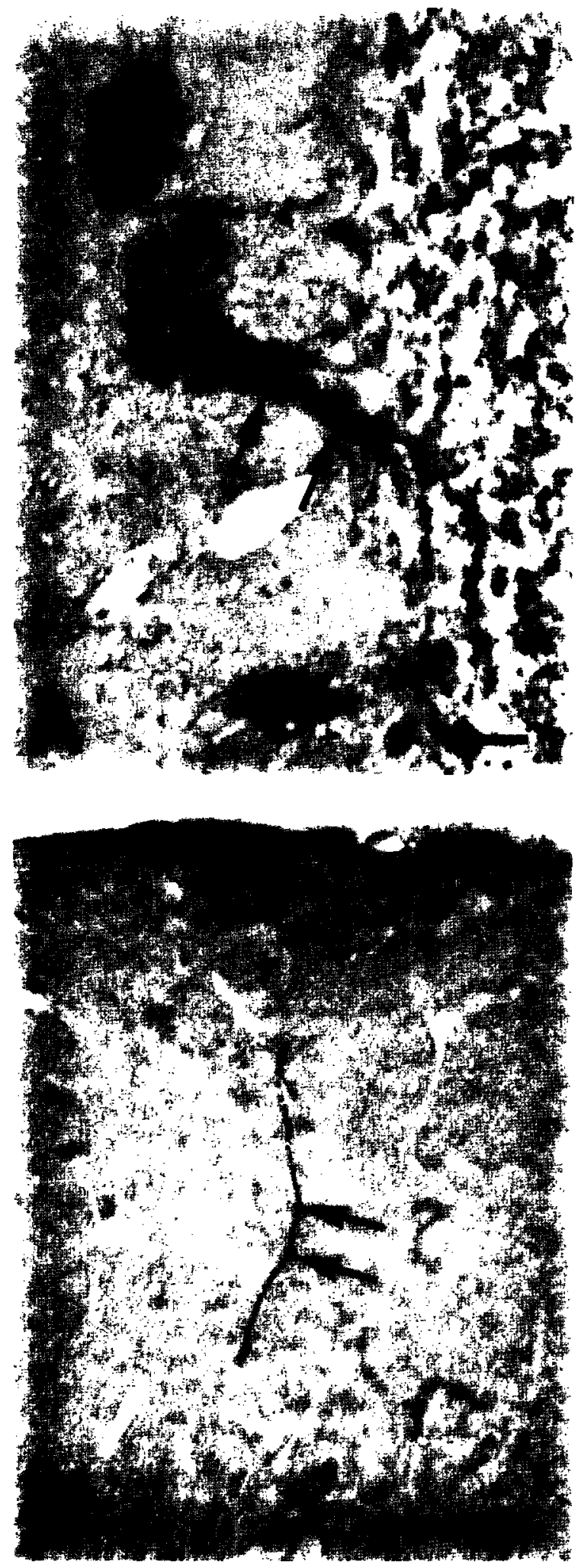

FIG. 2. Telencephalic dynorphin. Panel A shows punctate terminal immunoreactivity in 3 olfactory bulb glomeruli $(G)$. The center glomerulus appears to connect (arrows) with the olfactory nerve to the right which also contains immunoreactivity and may be the source of glomerular terminals. In Panel B, an immunoreactive fiber (arrows) is seen in lamina I of frontal cortex. Bars: $50 \mu \mathrm{m}$. small faintly immunoreactive dynorphin perikarya can be localized to the granule cell layer of the dentate gyrus. Also, in the dentate gyrus, dense fiber immunoreactivity is seen in the hilar region which gives rise to mossy fibers that project to hippocampal fields CA3 and CA2 (Fig. 3 C,D). No immunoreactivity was detected within field $\mathrm{CA} \mathrm{I}$.

In the diencephalon, the most prominent dynorphin-like immunoreactivity is situated within the hypothalamus in the supraoptic, paraventricular and other accessory magnocellular nuclei. In the supraoptic nucleus, many perikarya are dynorphin-immunoreactive (Fig. 4A), and further, their distribution corresponds to that of the vasopressin-containing neurons [77]. In the paraventricular nucleus, dynorphinpositive perikarya are distributed within the lateral subnucleus which is also vasopressin-rich. Other immunoreactive neurons are seen throughout hypothalamus, especially in its dorsolateral aspects (Fig. 4C). No parvocellular paraventricular perikarya are immunoreactive, although parvocellular dynorphin-positive perikarya exist in the arcuate nucleus. Immunoreactive dynorphin fibers are distributed in the above hypothalamic areas which contain positive perikarya.

In the mesencephalon, diffuse dynorphin immunoreactivity can be seen in the substantia nigra pars reticulata. Small dynorphin-positive perikarya are scattered dorsally and laterally in the mesencephalic reticular formation. Some of these perikarya are localized within the lateral tegmental nucleus. In the periaqueductal gray, dynorphin-positive perikarya are seen to be localized ventrally and laterally (Fig. 5A). These perikarya form a band continuous with other mesencephalic reticular perikarya described above. The position of the perikarya within the periaqueductal gray is somewhat different from the position of [Leu]enkephalincontaining perikarya, many of which appear to be situated more dorsally in this region (Fig. 5B). Furthermore, both dynorphin-positive and [Leu]enkephalin-positive neuronal populations exist outside the serotonergic nucleus raphe dorsalis (Fig. 5C). Some immunoreactive varicosities are also seen in the colliculi.

In the pons, dynorphin-containing perikarya and fibers are seen scattered throughout the reticular formation. Particular areas of density include the parabrachial nuclei (Fig. 6A), where immunoreactive perikarya appear to form a group separate from that containing [Leu]enkephalinpositive perikarya (Fig. 6B). A few scattered perikarya and fibers are situated adjacent to the nucleus locus coeruleus and in the mesencephalic nucleus of the trigeminal nerve (Fig. 6A). Within locus coeruleus, only occasional positive varicosities are encountered. Dynorphin-immunoreactive fibers are also seen in the main sensory nucleus of the trigeminal nerve, and the nucleus of the spinal tract as well as the spinal tract of the trigeminal nerve. More ventrally, positive varicosities can also be localized to the motor nucleus of the facial nerve.

In the medulla, as in the pons, many small positive dynorphin-containing perikarya and varicosities are scattered within the reticular formation. Laterally, dynorphinpositive varicosities and occasional small perikarya are seen within the nucleus of the spinal tract of the trigeminal nerve. Within the nucleus raphe magnus, a few beaded varicosities could be detected. Many scattered immunoreactive perikarya and fibers are seen in the noradrenergic nucleus A5 at the level of the superior olivary nucleus (Fig. 7C). More dorsally, immunoreactive fibers can be localized to the medial and spinal vestibular nuclei, as well as dorsal and ventral cochlear nuclei. In the caudal medulla. diffuse immunoreac- 


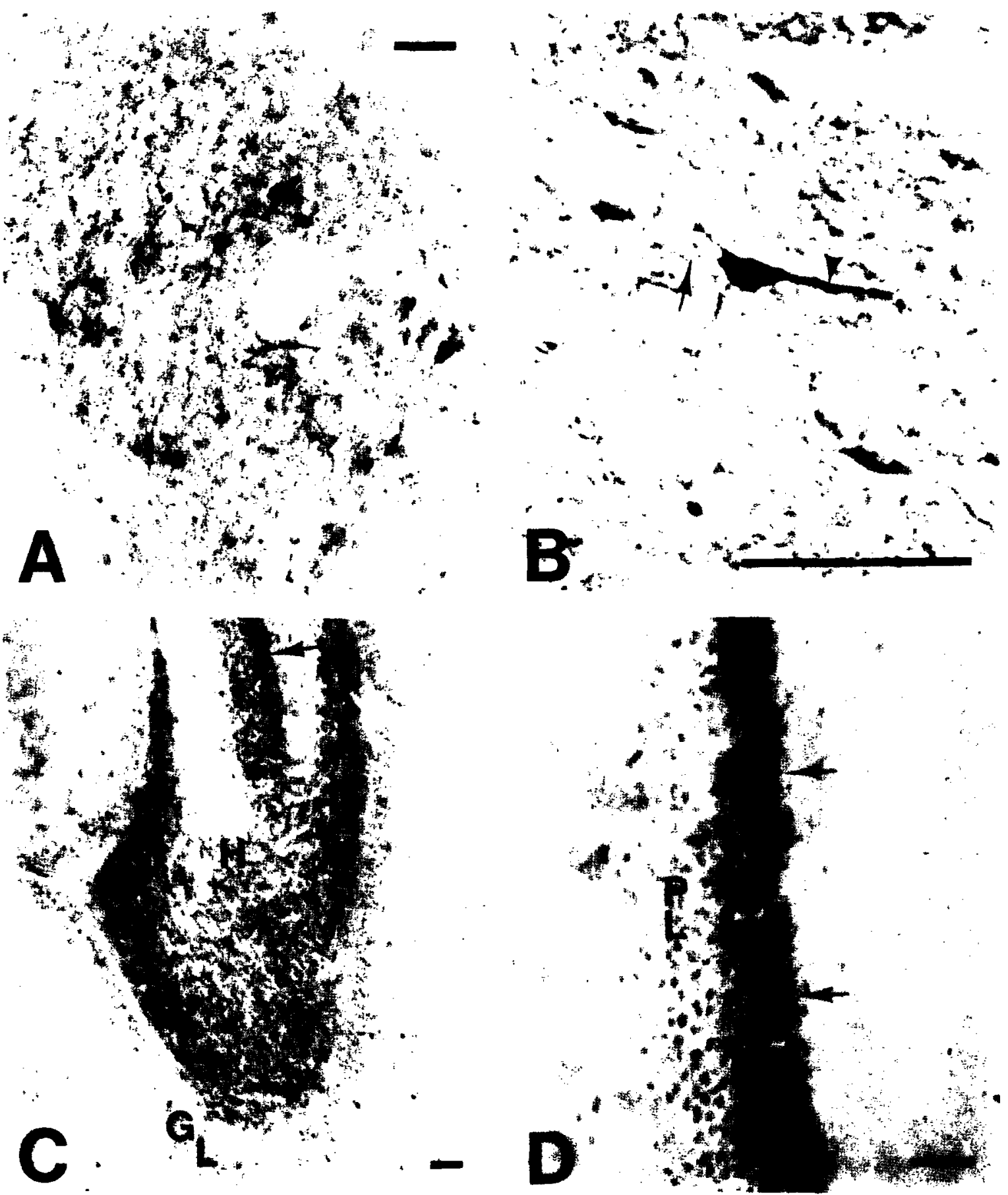

FIG. 3. Telencephalic dynorphin. Panel A depicts immunoreactive perikarya and fibers in the central amygdaloid nucleus. Panel B shows an immunoreactive neuron in lamina II of the entorhinal cortex. Note the slender axon (arrow) and the apical dendrite (arrow-head) directed toward the cortical surface. Hippocampal mossy fibers (arrows) are demonstrated in Panels C (dentate gyrus) and D (hippocampal field CA2). H: hilar region, GL: granule cell layer of dentate gyrus. PL: pyramidal cell layer of hippocampus. Bars: $50 \mu \mathrm{m}$.

tivity is seen in the inferior olivary complex in addition to the olivocerebellar tract. A few positive perikarya are also scattered within the lateral reticular nucleus among the noradrenergic perikarya of the A 1 cell group. Many small, positive dynorphin-containing perikarya and fibers are distributed in the nucleus tractus solitarius and among the noradrenergic cell group A2 (Fig. 7A,B). Dynorphin-positive perikarya were also noted in the nucleus cuneatus (Fig. 7D), and diffuse immunoreactivity was seen in the nucleus gracilis.

Finally, in the spinal cord, a few immunoreactive perikarya were observed in the marginal zone. Dynorphin immunoreactivity was also localized in varicosities scattered 

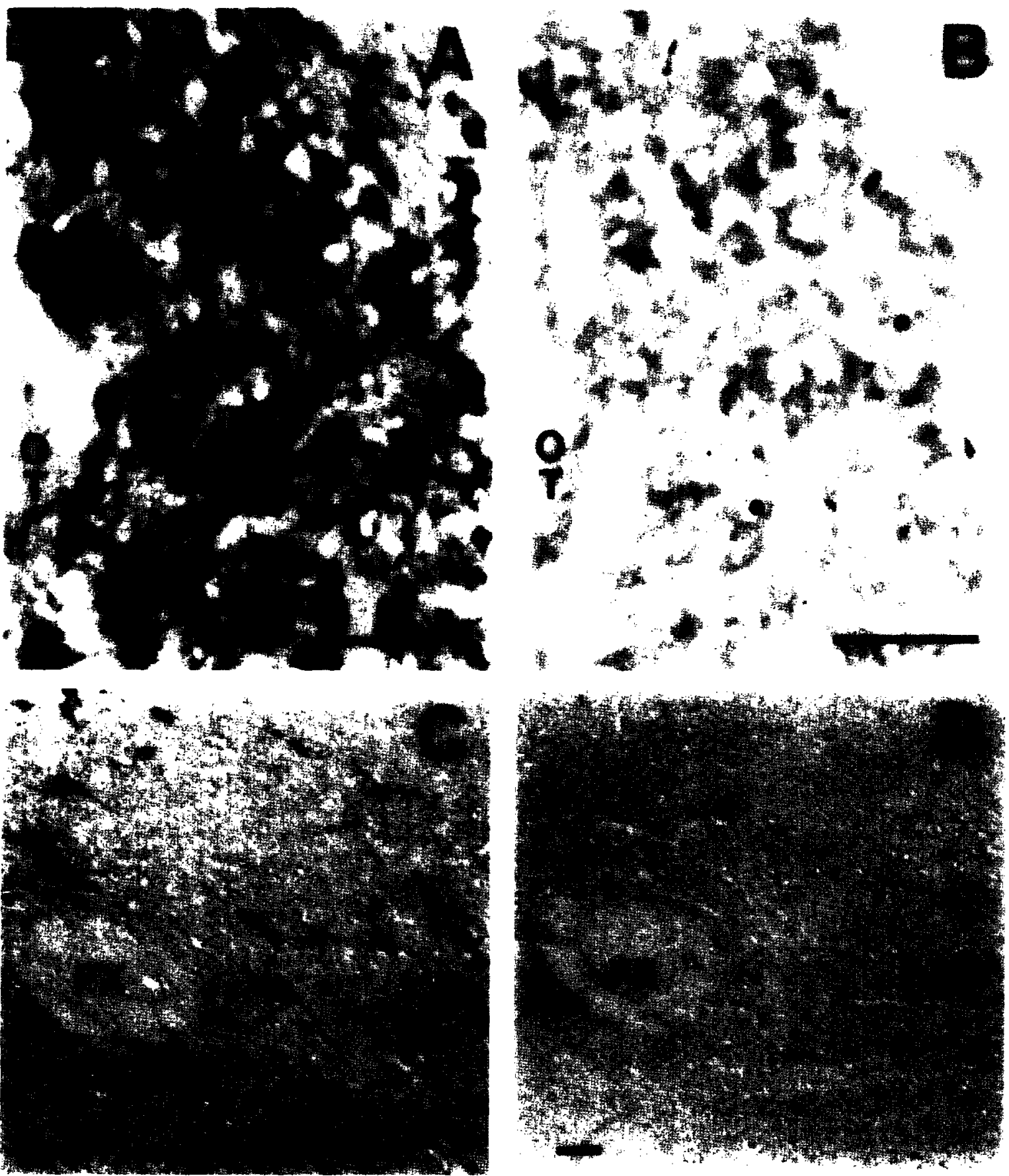

FIG. 4. Hypothalamic dynorphin. Panel A shows immunoreactive (dynorphin-17) magnocellular perikarya in the caudal supraoptic nucleus (OT: optic tract). At this level. the majority of magnocellular perikarya are known to be vasopressinergic. Panel $B$ is an adjacent section to Panel A demonstrating the complete blockade of immunoreactivity upon pre-adsorption with dynorphin-17 (see text). Panel C depicts magnocellular neurons in the posterolateral hypothalamus (FX: fornix), while in Panel D, lack of staining is demonstrated in an adjacent section blocked with dynorphin-17 (see text). Bars: $50 \mu \mathrm{m}$.

\section{FACING PAGE:}

FIG. 5. Mesencephalic periaqueductal gray. Panels A, B, and C are photomontaged serial sections through this region stained respectively with dynorphin-17, [Leu]enkephalin, and serotonin. Note position of the same capillary lumen (stars) in all three. Dynorphin immunoreactive neurons form a group situated ventrally and laterally within the periaqueductal gray (A), whereas [Leu]enkephalin-positive neurons are localized more dorsally (B). Note that both dynorphin and [Leu]enkephalin groups are outside the nucleus raphe dorsalis (C). Dashed line in Panel C demarcates the separation of dynorphin (Dyn) and enkephalin (Enk) regions. The insets in A and B are high power magnifications of each respective neuronal group. Arrows in A and B and their respective magnified areas, point to specific neuronal perikarya. AQ: cerebral aqueduct. Bars: $200 \mu \mathrm{m}$. Inset bars: $25 \mu \mathrm{m}$. 

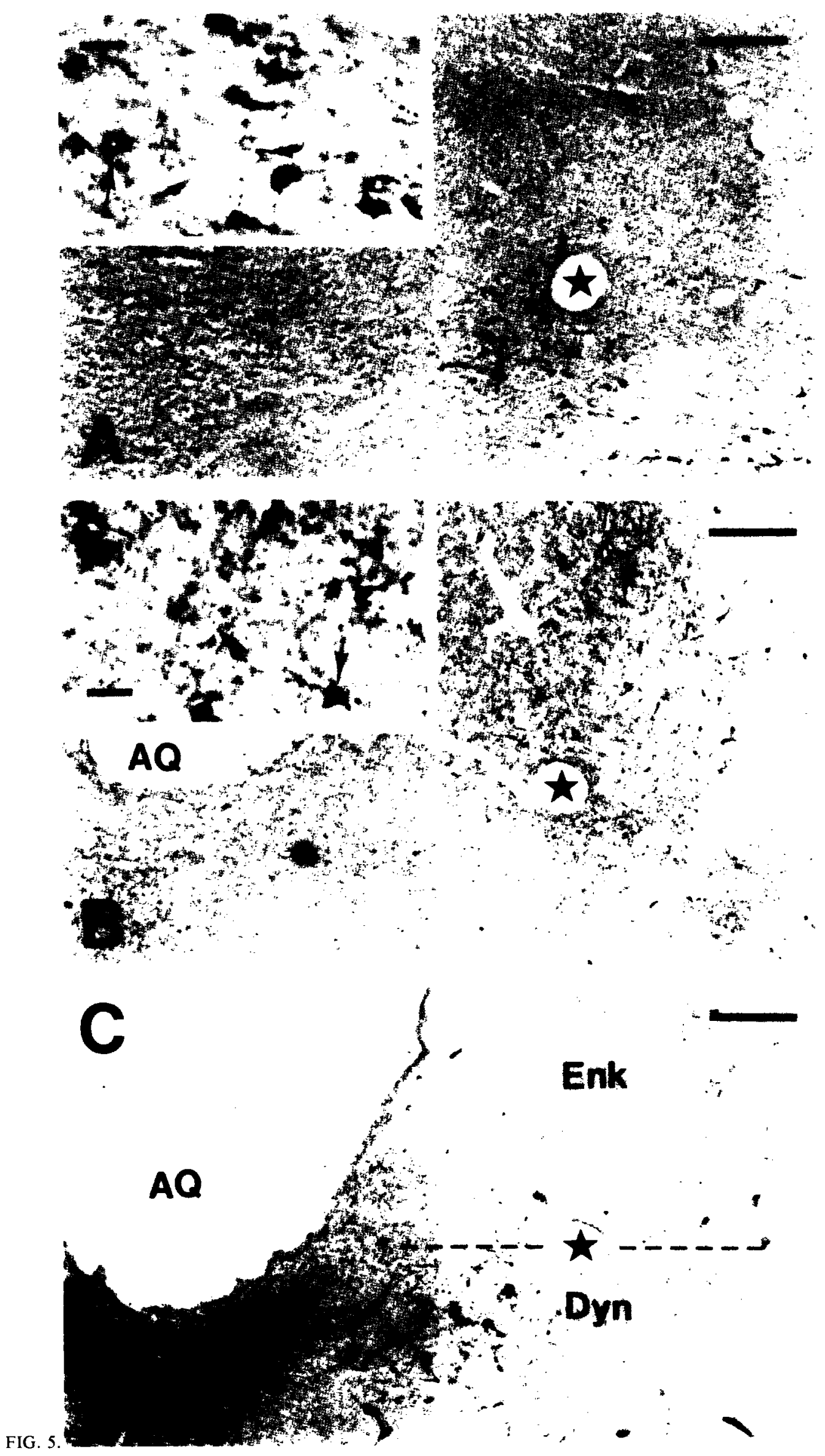

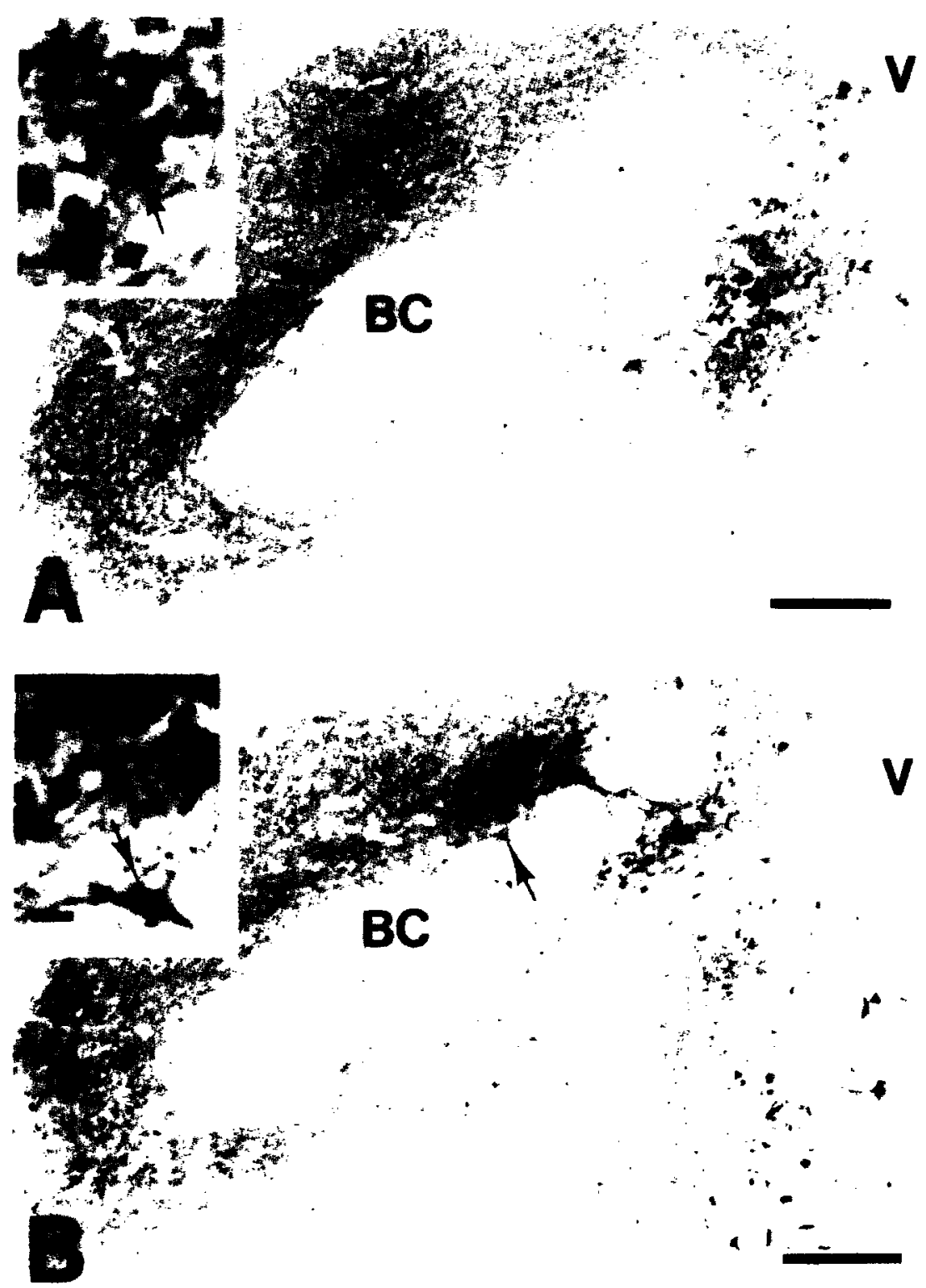

FIG. 6.
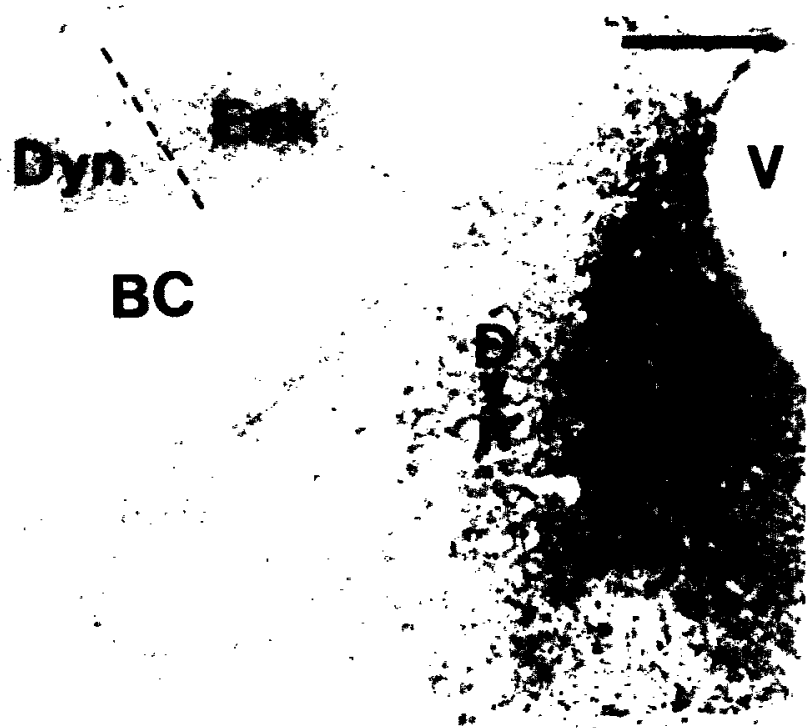

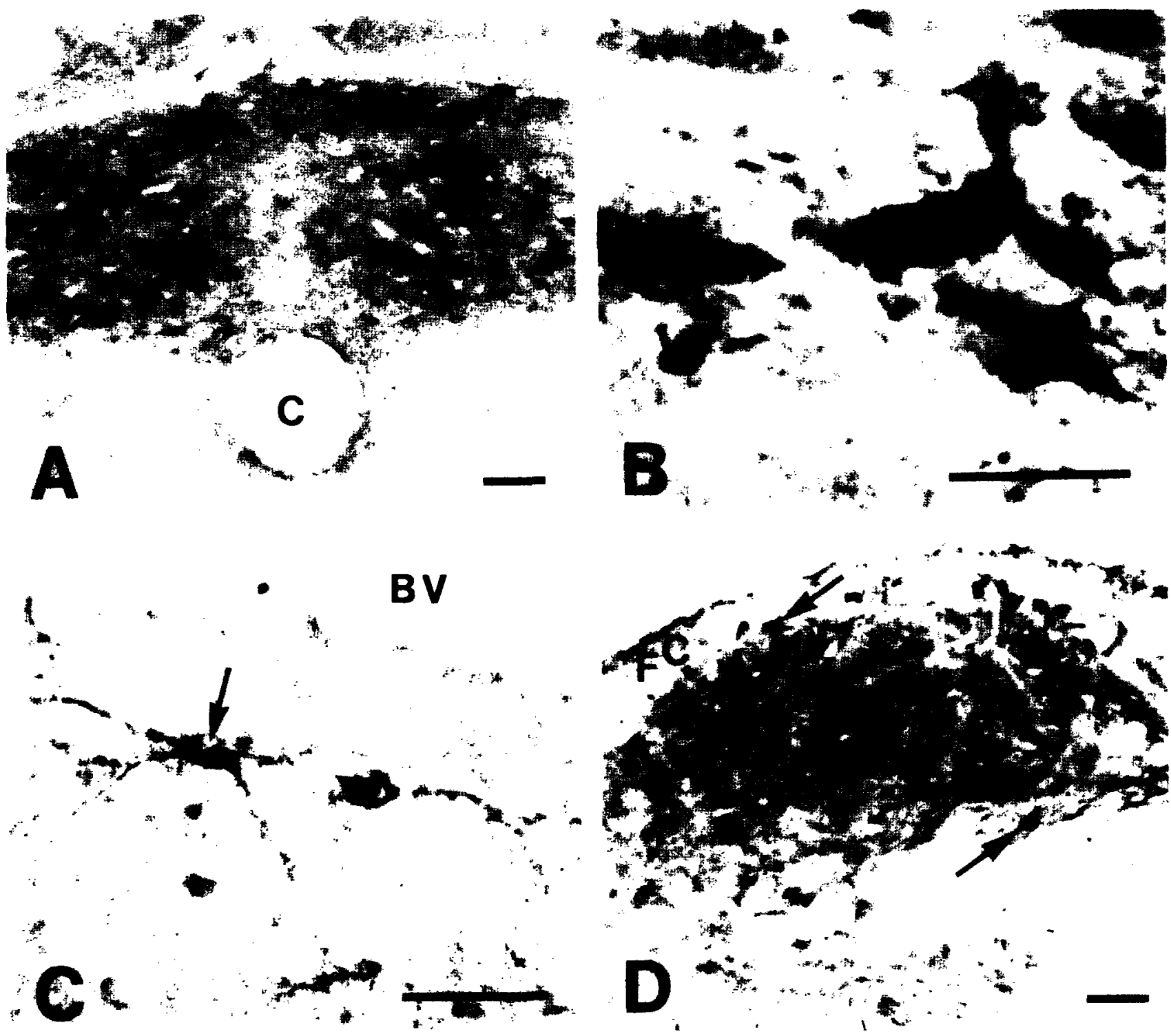

FIG. 7. Dynorphin in the medulla. Panel A shows immunoreactive perikarya (arrows) within the nucleus tractus solitarius (C: central canal). A few positively staining neurons of this nucleus are magnified in Panel B. Panel C depicts an immunoreactive neuron (arrow) with four processes, within the noradrenergic nucleus A5 (BV: blood vessel). In Panel D, numerous immunoreactive neurons (arrows) are seen in the nucleus cuneatus (FC: fasciculus cuneatus). Bars (A, C, D): $50 \mu \mathrm{m}$. Bar (B): $25 \mu \mathrm{m}$.

\section{FACING PAGE}

FIG. 6. Parabrachial nucleus, locus coeruleus. Panels A, B and C are adjacent sections stained respectively for dynorphin-17 [Leu] enkephalin, and tyrosine hydroxylase (noradrenergic nucleus locus coeruleus). Insets in A and B are higher magnifications of a specific region in each panel. Panel A depicts the position of dynorphin-positive perikarya in the parabrachial nucleus (arrow points to a specific neuron magnified in inset). [Leu]enkephalin perikarya (B) form a separate group in this region (arrow points to a specific neuron magnified in inset). In Panel $\mathrm{C}$, the position of the locus coeruleus is shown for comparative purposes. Note also the differential location of dynorphin (Dyn) and [Leu]enkephalin (Enk) immunoreactive perikarya (around dashed line) in the vicinity of the locus coeruleus and the mesencephalic nucleus of the trigeminal nerve (which also contains Dyn), immediately lateral to the locus coeruleus. BC: brachium conjunctivum. V: fourth ventricle. Bars: $200 \mu \mathrm{m}$. Inset bars: $10 \mu \mathrm{m}$. 
throughout the gray matter, but was particularly concentrated in the marginal zone and in immunoreactive patches in deeper laminae of the dorsal horn.

\section{DISCUSSION}

In the present study, rats given varying doses of colchicine were used to study the distribution of dynorphinpositive neuronal structures in the central nervous system. Colchicine acts to inhibit microtubule formation, and thereby reduce axonal transport of material synthesized in neurons $[12,16,38,52]$. The result is accumulation of peptides and proteins in the perikarya and an enhancement of the visual signal obtained by immunocytochemical staining of specific neuronal products. In our experiments, the utilization of high doses of colchicine $(300-400 \mu \mathrm{g} / 10 \mu \mathrm{l})$ has permitted the localization of peptides and proteins in the smallest neuronal elements, including enhanced visualization of perikarya, dendrites and axons. In particular, immunoreactive dynorphin-containing perikarya outside the hypothalamic magnocellular system are usually not visible with low doses of colchicine [78, 85, 86]. For example, Weber et al. [86], using lower doses of colchicine, were able to localize immunoreactive fibers but not perikarya in a few of the regions reported here. Although direct intracerebral injection of colchicine has been reported to induce neuronal damage [21], we have not detected evidence of neuronal damage in Nissl-stained sections obtained from animals receiving intraventricular colchicine injections. The large dose of colchicine used in some animals in these studies has resulted in improved visualization of dynorphin cell groups and therefore represents a substantial technical improvement. We are unsure of the precise chemical nature and size of the immunoreactivity in these tissues, but biochemical studies are in progress to address these issues. Other immunocytochemical studies in our laboratory are under way using untreated rats and rats with doses of colchicine ranging up to $400 \mu \mathrm{g}$, with antibodies against dynorphin-17, dynorphin-B, and $\alpha$-neo-endorphin. These studies show that the structures described in the present paper are indeed immunoreactive against all three pro-dynorphin produced peptides. Thus, the immunoreactivities present in these structures are most likely pro-dynorphin products.

Using antisera generated against various segments of the dynorphin molecule, we have localized dynorphin-immunoreactivity in a large number of brain areas and the spinal cord. Dynorphin-positive perikarya, fibers and terminals were found in the entorhinal cortex, central nucleus of amygdala, hippocampal dentate gyrus, hypothalamic magnocellular nuclei, mesencephalic periaqueductal gray, parabrachial nuclei, brain stem reticular formation, several monoaminergic nuclei, nucleus of the spinal tract of trigeminal nerve, nucleus tractus solitarius, nucleus cuneatus, and spinal cord. In addition, immunoreactive dynorphin fibers or terminals were localized to the cerebral cortex, olfactory bulb glomeruli, nucleus accumbens, caudate-putamen, globus pallidus, hippocampal mossy fibers, preoptic area, hypothalamus, substantia nigra pars reticulata, nucleus locus coeruleus, the trigeminal sensory nuclei, motor facial nucleus, nucleus raphe magnus, certain vestibular and cochlear nuclei, reticular formation and spinal gray matter, especially the marginal layer and the deeper laminae of the dorsal horn.

Dynorphin-like immunoreactivity can be distinguished from [Leu]enkephalin immunoreactivity in the brain. Since the [Leulenkephalin sequence (Tyr-Gly-Gly-Phe-Leu) is incorporated into the dynorphin peptide (at its $\mathrm{NH}_{2}$-terminus), the problem of cross-reactivity of antisera generated against either peptide cannot be ignored. To address this problem, we tested antisera against several fragments and the full sequence of the dynorphin molecule (i.e., 1-13, 7-17, 1-17). The results obtained using these antisera contrast with the immunocytochemical staining with anti-[Leu]enkephalin sera as well as antisera to an adrenal medullary pro-enkephalin fragment, BAM-22P [46]. Using serial section analysis and cross-blocking controls, dynorphin immunoreactivity was shown to be present in systems which are separate from, but often parallel to those containing enkephalin immunoreactivity [84]. As an example of a non-parallel system, the hypothalamic magnocellular nuclei including the supraoptic and paraventricular, all contain dynorphin-positive perikarya but not enkephalin-positive perikarya $[77,78]$. In the rat hypothalamus, we have observed perikaryal enkephalin immunoreactivity only within parvocellular neurons. However, immunoreactive magnocellular enkephalin perikarya have been reported in the rat [61] and cat [45] hypothalamus. It should be noted that dynorphin had not been sequenced at the time of these studies and was not eliminated as the source of immunoreactivity in the magnocellular neurons. Although [Leu]enkephalin could be present in magnocellular neurons as a result of processing of dynorphin, we did not observe enkephalin-like immunoreactivity in these neurons in the present study. An example of separate but adjacent dynorphin and enkephalin systems is found in the periaqueductal gray where dynorphin-positive perikarya occupy a more ventral position, lateral to the nucleus raphe dorsalis, whereas immunoreactive [Leu]enkephalin perikarya are situated somewhat more dorsally in the periaqueductal gray. Thus, dynorphin-like and enkephalin-like immunoreactivity are often present in the same brain region, although they are localized in different neuronal systems [84].

In the olfactory bulb, punctate dynorphin immunoreactivity was localized in some but not all glomeruli. Furthermore, this immunoreactivity might originate from the olfactory nerve. In contrast, immunoreactive [Leu]-enkephalin is found in most glomeruli of the bulb (Khachaturian et al., $J$. Neurosci., in press). However, the origin of the opioid peptidergic innervation of the olfactory bulb glomeruli requires further study. In other telencephalic structures, dynorphincontaining and enkephalin-containing systems have been difficult to differentiate. These structures include the nucleus accumbens, caudate-putamen, globus pallidus, as well as the central nucleus of the amygdala, hippocampus and entorhinal cortex. In the central nucleus of amygdala, only a few scattered perikarya are dynorphin-positive whereas considerably more [Leu]enkephalin perikarya can be detected. In the lateral entorhinal cortex, a few scattered dynorphin-positive perikarya can be seen in layer II. Some layer II cells are known to project via the perforant path to the stratum moleculare of the dentate gyrus $[28,67]$. So far, we have observed very few dynorphin-like immunoreactive fibers within the perforant path. In contrast, a distinct [Leu]enkephalinergic system exists in the lateral entorhinal cortex which appears to project via the perforant path to the dentate gyrus ([20] Khachaturian et al., J. Neurosci., in press). Within the dentate gyrus, dense immunoreactivity can be seen in the mossy fiber system, which constitutes the projection of the granule cells to hippocampal fields CA3 and CA2 [4,68]. A few faint dynorphin-positive perikarya are present in the stratum granulosum which are presumably the source of mossy fiber immunoreactivity. Enkephalin-like immunoreactivity has also been demonstrated in the mossy 
fiber system ([20] Khachaturian et al., $J$. Neurosci., in press).

In the mesencephalon, substantia nigra exhibits diffuse dynorphin-positive immunoreactivity in the pars reticulata, whereas the main distribution of enkephalin appears to be in the form of punctate varicosities distributed dorsally in the pars compacta among dopaminergic neurons. Other monoamine-containing nuclei containing dynorphin-like immunoreactivity include the locus coeruleus, raphe dorsalis, raphe magnus, and the $\mathrm{Al}, \mathrm{A} 2$ and $\mathrm{A} 5$ noradrenergic cell groups of Dahlstrom and Fuxe [13]. The A2 cell group is localized within the nucleus tractus solitarius and dorsal motor nucleus of the vagus nerve. Many small immunoreactive dynorphin perikarya are also seen in this region as are [Leu]enkephalin-positive perikarya. Neither the projections of these dynorphin-containing cells, nor their relationship to those containing enkephalin or norepinephrine is clear at present.

In other brain stem regions examined, dynorphin-positive fibers were noted in the mesencephalic, main, and spinal sensory nuclei of the trigeminal nerve. The nucleus of the spinal tract of the trigeminal nerve and nucleus cuneatus also contain dynorphin-positive perikarya. Moreover, some of the vestibular nuclei and the motor nucleus of the facial nerve contain immunoreactive dynorphin fibers. In the parabrachial nuclei, dynorphin-positive perikarya were noted to form a separate group distinct from that containing [Leu]enkephalin-positive perikarya.

Lastly, in the spinal cord, both perikaryal and diffuse immunoreactivity were seen in the marginal zone. In addition, distinct patches of dynorphin immunoreactive varicosities were noted in the deeper laminae of the dorsal horn as well as scattered fibers throughout the gray matter. [Leu]enkephalin fiber immunoreactivity is prominent in the marginal zone of the dorsal horn and is also localized to intrinsic spinal interneurons. At present the distinction between dynorphin and [Leu]enkephalin immunoreactivities in the spinal cord is not clear.

The widespread distribution of dynorphin-immunoreactive perikarya and fibers in brain indicates that this opioid peptide might have a role in diverse physiological functions. Unfortunately, in vivo studies of dynorphin are complicated by its marked sensitivity to enzymatic degradation $[24,27,88]$. Nevertheless, our anatomical results indicate that several possible physiological roles of dynorphin in brain should be considered. For example, the colocalization of dynorphin and vasopressin in the same hypothalamic magnocellular neurons [77] may indicate a coordinate role for these peptides, analogous to that proposed for other multi-neurotransmitter systems (cf. [1]).

The results of the present study suggest that sensory functions might be influenced by dynorphin at several levels of the central nervous system. The presence of immunoreactive dynorphin perikarya and fibers in the periaqueductal gray and fibers in nucleus raphe magnus may indicate a role in nociception $[2,3]$. While in vivo microinjection of dynorphin-(1-13) into the periaqueductal gray or cerebral ventricles did not induce analgesia as measured by the tail-flick and vocalization threshold tests $[19,73,88]$, another study using a different measure of pain sensitivity did obtain an analgesic effect [54]. The presence of immunoreactive perikarya and processes in the dorsal horn of the spinal cord is consistent with a possible role in nociception $[8,14]$. More specifically, the observation of immunoreactive patches in deeper laminae of the dorsal horn might indicate a possible role for dynorphin in influencing those second order nociceptive neurons with perikarya localized in deeper laminae and with axons that ascend to several contralateral reticular areas, including periaqueductal gray.

At the level of the medulla, dynorphin-positive perikarya in the nucleus cuneatus might receive axons projecting through the fasciculus cuneatus from the cervical and upper thoracic dorsal root ganglia, which convey proprioceptive and very specific tactile input. Extending through the pons and medulla, dynorphin-immunoreactive perikarya and fibers in the nucleus of the spinal tract of the trigeminal nerve could form part of the circuitry which processes input from the vagal, glossopharyngeal and facial nerve fibers in the spinal trigeminal tract which itself contains immunoreactive fibers. Neurons in this nucleus are exquisitely sensitive to tactile input and are involved in pain impulse transmission as well $[39,40]$. The main sensory nucleus of the trigeminal nerve, which contains dynorphin-immunoreactive fibers, receives tactile and pressure input from the head. The mesencephalic nucleus of the trigeminal nerve, which receives proprioceptive input relating to mastication, contains both immunoreactive perikarya and fibers. The motor nucleus of the facial nerve contains immunoreactive fibers which could arise from dynorphin-positive perikarya seen in the nucleus of the spinal tract of the trigeminal nerve; the pathway connecting these nuclei is involved in corneal and other trigeminofacial reflexes [70]. Dynorphin could also be involved in processing vestibular input since immunoreactive fibers are present in both the medial and spinal vestibular nuclei. The presence of a large number of immunoreactive perikarya and fibers in nucleus tractus solitarius is particularly suggestive of a role for dynorphin in modulating visceral reflex mechanisms, particularly the baroreceptor arc [53]. It is interesting that many of the ascending projections of nucleus tractus solitarius are to other areas containing dynorphin immunoreactivity, including the parabrachial nuclei [37.51], the paraventricular and arcuate nuclei of hypothalamus, the central nucleus of the amygdala and the medial preoptic area [57]. Exteroceptive sensory processing areas containing dynorphin-immunoreactive fibers include the superior and inferior colliculi and some glomeruli of the olfactory bulb.

Dynorphin may also be involved in the regulation of motor activity, as indicated by the presence of immunoreactive fibers and terminals in nucleus caudate-putamen, globus pallidus, nucleus accumbens and the pars reticulata of substantia nigra. Other possible loci of motor regulation include the inferior olivary complex and olivocerebellar tract which contained diffuse immunoreactivity; however, no immunoreactive fibers could be observed in cerebellum although it contains immunoassayable levels of dynorphin [23]. In support of a role in motor activity, intracerebroventricular administration of dynorphin-(1-13) in mice results in both eating and grooming behavior [73].

Our anatomical observations have demonstrated the separateness of dynorphin from other opioid peptide systems in brain, confirming studies indicating their separate biosynthetic origins $[11,26,36,43,48,50,58]$. Nevertheless, dynorphin and enkephalin immunoreactivity frequently appear in spatially contiguous positions, raising the question of how the "messages" of these peptides are differentiated postsynaptically. A number of studies using in vitro bioassays and radioreceptor assays have demonstrated the existence of multiple subtypes of opiate receptors $[9,25,41,42$, $59,63,65]$. Morphine, D $[\text { Ala }]^{2}, \mathrm{D}[\text { Leu }]^{5}$-enkephalin and 
ethylketocyclazocine are considered to be prototype ligands for the mu, delta and kappa opiate receptor subtypes, respectively. In vitro studies have shown that dynorphin has a higher affinity for kappa than other opiate receptor subtypes, with the magnitude of difference depending upon the tissue preparation and incubation conditions $[10,33,56,87]$. In contrast, the enkephalins, particularly [Leu]enkephalin, exhibit a higher affinity for the delta opiate receptor subtype [42]. Thus, dynorphin and enkephalin can be discriminated at the receptor level, although differential postreceptor events elicited by these interactions remain to be characterized. These considerations indicate that the potentiality of enzymatic conversion of some dynorphin to [Leu]enkephalin represents a means by which dynorphin neurons could change the "address" of the opioid "message," transmitting varying proportions of kappa-directed and delta-directed opioids to the receptor sites in the synapse. Accordingly, we are attempting to determine whether enkephalin immunoreactivity is present in a subset of dynorphin neurons in brain.

\section{ACKNOWLEDGEMENTS}

This work was supported by NIDA grant DA02265. NIDA Center grant DA00154 and Theophile Raphael Fund to SJW and HA NIMH Training Grant MH15794 to HK; John G. Searle Clinical Pharmacology Fellowship to MEL; NIDA grant DAl199 to AG. The authors wish to thank M. van der Veen, G. Baldrighi, S. Burke and $\mathrm{K}$. Shiomi for their expert assistance and M. Ritchie for manuscript preparation.

\section{REFERENCES}

1. Akil, H. and S. J. Watson. B-END and biosynthetically related peptides in the CNS. In: Handbook of Psychopharmacology, edited by L. Iversen, S. Iversen and S. Snyder. New York: Plenum Publishing. In press.

2. Akil, H., and S. J. Watson. The role of endogenous opiates in pain control. In: Pain and Society, edited by H. W. Kosterlitz and L. Y. Terenius. New York: Springer-Verlag, Chemie Gmbh, 1980, pp. 201-222.

3. Behbehani, M. M. and H. L. Fields. Evidence that an excitatory connection between the periaqueductal gray and nucleus raphe magnus mediates stimulation produced analgesia. Brain Res. 170: 85-93, 1979.

4. Blackstad, T. W., K. Brink, J. Hem and B. Jeune. Distribution of hippocampal mossy fibers in the rat. An experimental study with silver impregnation methods. $J$. comp. Neurol. 138: 443$450,1970$.

5. Bloch, B., C. Bugnon, D. Fellman and D. Lenys. Immunocytochemical evidence that the same neurons in the human infundibular nucleus are stained with anti-endorphins and antisera of other related peptides. Neuorsci. Lett 10: 147-152, 1978.

6. Bloom, F. E., E. Battenberg, J. Rossier, N. Ling and R. Guillemin. Neurons containing beta-endorphin in rat brain exist separately from those containing enkephalin: Immunocytochemical studies. Proc. natn. Acad. Sci. U.S.A. 75: 1591-1595, 1978.

7. Bloom, F. E., J. Rossier, E. L. F. Battenberg. A. Bayon, E. French, S. J. Henricksen, G. R. Siggins, D. Segal. R. Browne, N. Ling and R. Guillemin. Beta-Endorphin: Cellular localization, electrophysiological and behavioral effects. In: The Endorphins: Advances in Biochemical Psychopharmacology, vol. 18 edited by E. Costa and M. Trabucchi. New York: Raven Press. 1978 , pp. 89-109.

8. Botticelli, L. J., B. M. Cox, and A. Goldstein. Immunoreactive dynorphin in mammalian spinal cord and dorsal root ganglia. Proc. natn. Acad. Sci. U.S.A. 78: 7783-7786, 1981

9. Chang, K-J., B. R. Cooper, E. Hazum and P. Cuatrecasas. Multiple opiate receptors: Different regional distribution in the brain and differential binding of opiates and opioid peptides. Molec. Pharmac. 16: 91-104, 1979.

10. Chavkin, C., I. F. James and A. Goldstein. Dynorphin is a specific endogenous ligand of the kappa opioid receptor. Science 215: 413-415, 1982.

11. Comb, J., P. H. Seeburg, J. Adelman, L. Eiden and E. Herbert. Primary structure of the human Met- and Leu-enkephalin precursor and its mRNA. Nature 295: 663-666, 1982.

12. Dahlstrom, A. Effect of colchicine on transport of amine storage granules in sympathetic nerves of rat. Eur. J. Pharmac. 5: 111 $113,1968$.
13. Dahlstrom, A.. and F. Fuxe. Evidence for the exitence of monoamine-containing neurons in the central nervous system. I. Demonstration of monoamines in the cell bodies of brain stem neurons. Acta physiol. scan. 62: suppl 232, 3-55, 1964.

14. Duggan, A. W., J. G. Hall and P. M. Headley. Morphine, enkephalin and the substantia gelatinosa. Nature 264: 456-458. 1976.

15. Elde, R.. T. Hokfelt, O. Johansson and L. Terenius. Immunohistochemical studies using antibodies to leucineenkephalin: Initial observations on the nervous system of the rat. Neuroscience 1: 349-351, 1976.

16. Fink, B. R., M. Byers and M. Middaugh. Dynamics of colchicine effects on rapid axonal transport and axonal morphology. Brain Res. 56: 299-311, 1973.

17. Finley. J. C. W., P. Lindstrom and P. Petrusz. Immunocytochemical localization of beta-endorphin-containing neurons in the rat brain. Neuroendocrinology 33: 28-42, 1981.

18. Finley, J. C. W., J. L. Maderdrut and P. Petrusz. The immunocytochemical localization of enkephalin in the central nervous system of the rat. J. comp. Neurol. 198:541-565, 1981.

19. Friedman, H. J., M. Jen, J. K. Chang, N. M. Lee and H. H. Loh. Dynorphin: A possible modulatory peptide on morphine or $\beta$-endorphin analgesia in the mouse. Eur. J. Pharmac. 69: 357360,1981

20. Gall. C., N. Brecha, J. J. Karten and K-J. Chang. Localization of enkephalin-like immunoreactivity to identified axonal and neuronal populations of the rat hippocampus. J. comp. Neurol. 198: 335-350. 1981

21. Goldschmidt, R. B. and O. Steward. Neurotoxic effects of colchicine: Differential susceptibility of CNS neuronal populations. Neuroscience 7: 695-714, 1982.

22. Goldstein, A.. W. Fischli. L. I. Lowney, M. Hunkapiller and L. Hood. Porcine pituitary dynorphin: Complete amino acid sequence of the biologically active heptadecapeptide. Proc. natn. Acad. Sci. U.S.A. 78: 7219-7223, 1981.

23. Goldstein, A., and V. E. Ghazarossian. Immunoreactive dynorphin in pituitary and brain. Proc. natn. Acad. Sci. U.S.A. 77: 6207-6210, 1980.

24. Goldstein. A.. S. Tachibana, L. I. Lowney, M. Hunkapiller and L. Hood. Dynorphin-(1-13), an extraordinary potent opioid peptide. Proc. natn. Acad. Sci. U.S.A. 76: 6666-6670, 1979.

25. Goodman, R. R., S. H. Snyder, J. J. Kuhar and W. S. Young III. Differentiation of delta and mu opiate receptor localizations by light microscopic autoradiography. Proc. natn. Acad. Sc $i$. U.S.A. 77: 6239-6243, 1980

26. Gubler, U., P. Seeburg, B. J. Hoffman, L. P. Gage and S. Udenfriend. Molecular cloning established proenkephalin as precursor of enkephalin-containing peptides. Nature 295: 206$208,1982$. 
27. Herman, B. H., F. Leslie and A. Goldstein. Behavioral effects and in vivo degradation of intraventricularly administered dynorphin-(1-13) and D-Ala ${ }^{2}$-dynorphin-(1-11) in rats. Life Sci. 27: 883-892, 1980.

28. Hjorth-Simonsen, A. Projections of the lateral part of the entorhinal area to the hippocampus and fascia dentata. J. comp. Neurol. 145: 219-232, 1972.

29. Hokfelt, T., R. Elde, O. Johansson, L. Terenius and L. Stein. The distribution of enkephalin-immunoreactive cell bodies in the rat central nervous system. Neurosci. Lett. 5: 25-31, 1977.

30. Hokfelt, T., A. Ljungdahl. L. Terenius, R. Elde and C. Nilsson. Immunohistochemical analysis of peptide pathways possibly related to pain and analgesia: Enkephalin and substance P. Proc. natn. Acad. Sci. U.S.A. 74: 3081-3085. 1977.

31. Hokfelt, T., L. Terenius, H. G. J. M. Kuypers and O. Dann. Evidence for enkephalin immunoreactive neurons in the medulla oblongata projecting to the spinal cord. Neurosci. Lett. 14: 55-60. 1979.

32. Hollt, V., I. Haarmann, K. Bovermann. M. Jericz and A. Herz. Dynorphin-related immunoreactive peptides in rat brain and pituitary. Neurosci. Lett. 18: 149-153, 1980.

33. Huidobro-Toro, J. P., K. Yoshimura, N. M. Lee, H. H. Loh and E. L. Way. Dynorphin interaction at the kappa-opiate site. Eur. J. Pharmac. 72: 265-266, 1981.

34. Jacobowitz, D. M., M. A. Silver and W. G. Soden. Mapping of [Leu]enkephalin containing axons and cell bodies of the rat forebrain. In: Endorphins in Mental Health Research, edited by E. Usdin. New York: Oxford University Press, 1979, pp. 62-74.

35. Kakidani, H., Y. Furutani, H. Takahashi, M. Noda, Y. Morimoto, T. Hirose, M. Asai, S. Inayama, S. Nakanishi and S. Numa. Cloning and sequence analysis of cDNA for procine $\beta$-neo-endorphin/dynorphin precursor. Nature 298: 245-249, 1982.

36. Kimura, S., R. V. Lewis, A. S. Stern, J. Rossier, S. Stein and S. Udenfriend. Probable precursors of [Leu] and [Met]enkephalin in adrenal medulla: Peptides of 3-5 kilodaltons. Proc. natn. Acad. Sci. U.S.A. 77: 1681-1685, 1980.

37. Koh, E. T. and J. A. Ricardo. Afferents and efferents of the parabrachial region in the rat: Evidence for parallel ascending gustatory versus visceroceptive systems arising from the nucleus of the solitary tract. Anat. Rec. 190: 449, 1978.

38. Kreutzberg, G. W. Neuronal dynamics and axonal flow. IV. Blockage of intraaxonal transport by colchicine. Proc. natn. Acad. Sci. U.S.A. 62: 722-728, 1969.

39. Kruger, L. and F. Michel. A morphological and somatotopic analysis of single unit activity in the trigeminal sensory complex of the cat. Expl Neurol. 5: 139-156, 1962.

40. Kruger, L. and F. Michel. Reinterpretation of the representation of pain based on physiological excitation of single neurons in the trigeminal sensory complex. Expl Neurol. 5: 157-178. 1962.

41. Lewis, M. E., M. Mishkin, E. Bragin, R. M. Brown, C. B. Pert and A. Pert. Opiate receptor gradients in monkey cerebral cortex: Correspondence with sensory processing hierarchies. Science 211: 1166-1169, 1981 .

42. Lord, J. A. H., A. A. Waterfield, J. Hughes and H. W. Kosterlitz. Endogenous opioid peptides: Multiple agonists and receptors. Nature 267: 495-499, 1977.

43. Mains, R. E., B. A. Eipper and N. Ling. Common precursor to corticotropins and endorphins. Proc. natn. Acad. Sci. U.S.A. 74: 3014-3018, 1977.

44. March, A. C., I. Parikh and P. Cuatrecasas. A simplified method for cyanogen bromide activation of agarose for affinity chromatography. Analvt. Biochem. 60: 149-152, 1974.

45. Micevych. $P$. and R. Elde. The relationship between enkephalinergic neurons and the vasopressin-oxytocin neuroendocrine system of the cat: An immunohistochemical study. J. comp. Neurol. 190: 135-146, 1980.
46. Mizuno, K., N. Minamino, K. Kangawa and H. Matsuo. A new family of endogenous "big" [Met]enkephalins from bovine adrenal medulla: Purification and structure of docosa-(BAM-22P) and eicosapeptide (BAM-20P) with very potent opiate activity. Biochem. biophys. Res. Commun. 97: 1283-1290, 1980.

47. Nakao, K., T. Yoshimasa, S. Oki. I. Tanaka, Y. Nakai, M. Wakimasu, M. Fujino and $H$. Imura. Presence of dynorphin-like immunoreactivity in rat pituitary gland and hypothalamus. $R e$ gul. Peptides 2: 201-208, 1981.

48. Nakanishi, S., A. Inoue, T. Kita, M. Nakamura, A. C. Y Chang, S. N. Sohen and S. Numa. Nucleotide sequence of cloned cDNA for bovine corticotropin-B-LPH precursor. $\mathrm{Na}$ ture 278: 423-427, 1979.

49. Nilaver, G., E. A. Zimmerman, R. Defendini, A. Liotta, D. A. Krieger and M. J. Grownstein. Adrenocorticotropin and $\beta$-lipotropin in the hypothalamus. Localization in the same arcuate neurons by sequential immunocytochemical procedures. J. Cell Biol. 81: 50-58, 1979.

50. Noda, M., Y. Furutani, H. Takahashi, M. Toyosato, T. Hirose, S. Inayama, S. Nakanishi and S. Numa. Cloning and sequence analysis of cDNA for bovine adrenal pre- proenkephalin. $\mathrm{Na}$ ture 295: 202-206, 1982.

51. Norgren, R. and C. M. Leonard. Ascending central gustatory pathways. J. comp. Neurol. 150: 217-238, 1973.

52. Norstrom, A., H. A. Hansson and J. Sjostrand. Effects of colchicine on axonal transport and ultrastructure of the hypothalamo-neurohypophyseal system of the rat. Z. Zellforsch. 113: 271-293, 1971.

53. Palkovits, M. and L. Zaborszky. Neuroanatomy of central cardiovascular control. Nucleus tractus solitarii: Afferent and efferent neuronal connections in relation to the baroreceptor arc. In: Hypertension and Brain Mechanisms, Progress in Brain Research, vol. 47, edited by W. DeJong, A. P. Provoost and A. P. Shapiro. Amsterdam: Elsevier/North Holland, 1978, pp. 9-34.

54. Petrie, E. C., S. T. Tiffany, T. B. Baker and J. L. Dahl. Dynorphin-(1-13): analgesia, hypothermia, cross-tolerance with morphine and $\beta$-endorphin. Peptides 3: 41-47, 1982.

55. Pickel, V. M., K. K. Sumal, S. C. Beckley, R. J. Miller and D. J. Reis. Immunocytochemical localization of enkephalin in the neostriatum of rat brain: A light and electron microscopic study. J. comp. Neurol. 189: 721-740, 1980.

56. Quirion. R., and C. B. Pert. Dynorphins: Similar relative potencies on mu, delta and kappa-opiate receptors. Eur. $J$. Pharmac. 76: 467-468, 1981.

57. Ricardo, J. A. and E. T. Koh. Anatomical evidence of direct projections from the nucleus of the solitary tract to the hypothalamus, amygdala and other forebrain structures in the rat. Brain Res. 153: 1-26, 1978.

58. Roberts, J. L. and E. Herbert. Characterization of a common precursor to corticotropin and beta-lipotropin: Identification of beta-lipotropin peptides and their arrangement relative to corticotropin in the precursor synthesized in a cell-free system. Proc. natn. Acad. Sci. U.S.A. 74: 5300-5304, 1977.

59. Robson, L. E. and H. W. Kosterlitz. Specific protection of the binding sites of D-Ala ${ }^{2}$-D-Leu ${ }^{5}$-enkephalin (delta-receptors) and dihydromorphine (mu-receptors). Proc. R. Soc. 205: 425232, 1979

60. Rossier, J., E. Battenberg, O. Pittman, A. Baron, L. Koda, R. Miller, R. Guillemin and F. Bloom. Hypothalamic enkephalin neurons may regulate the neurohypophysis. Nature 237: 653655, 1979.

61. Rossier, J., Q. Pittman, F. Bloom and R. Guillemin. Distribution of opioid peptides in the pituitary: A new hypothalamicpars nervosa enkephalinergic pathway. Fedn Proc. 39: 2555$2560,1980$.

62. Sar, M., W. E. Stumpf, R. J. Miller, K-J. Chang and P. Cuatrecasas. Immunohistochemical localization of enkephalin in rat brain and spinal cord. J. comp. Neurol. 182: 17-38, 1978.

63. Schulz, R., M. Wuster, H. Krenss and A. Herz. Selective development of tolerance without dependence in multiple opiate receptors of mouse vas deferens. Nature 285: 242-243, 1980. 
64. Simantov, R., M. J. Kuhar, G. R. Uhl and S. H. Snyder. Opioid peptide enkephalin: Immunohistochemical mapping in rat central nervous system. Proc. natn. Acad. Sci. U.S.A. 74: 2167$2171,1977$.

65. Smith, J. R. and E. J. Simon. Selective protection of stereospecific enkephalin and opiate binding against inactivation by N-ethylmaleimide: Evidence for two classes of opiate receptors. Proc. natn. Acad. Sci. U.S.A. 77: 281-284, 1980.

66. Sofroniew, M. V. Immunoreactive B-endorphin and ACTH in the same neurons of the hypothalamic arcuate nucleus in the rat. Am J. Anat. 154: 283-289, 1979.

67. Steward, O. Topographic organization of the projections from the entorhinal area to the hippocampal formation of the rat. $J$. comp. Neurol. 167: 285-314, 1976.

68. Swanson, L., J. Wyss and W. M. Cowan. An autoradiographic study of the organization of intrahippocampal association pathways in the rat. $J$. comp. Neurol. 181: 681-716, 1978.

69. Tachibana, S. . K. Araki, S. Ohya and S. Yoshida. Isolation and structure of dynorphin, an opioid peptide. from porcine duodenum. Nature 295: 339-340, 1982.

70. Truex. R. C. and M. B. Carpenter. Human Neuroanutomy, 6th edition. Baltimore: Williams and Wilkins Co., 1969.

71. Uhl, G. R., M. J. Kuhar and S. H. Snyder. Enkephalincontaining pathway: Amygdaloid efferents in the stria terminalis. Brain Res. 149: 223-228, 1978.

72. Uhl, G. R., R. R. Goodman, M. J. Kuhar, S. R. Childers and S. H. Snyder. Immunocytochemical mapping of enkephalin containing cell bodies. fibers and nerve terminals in the brain stem of the rat. Brain Res. 116: 75-94, 1979.

73. Walker, J. M. . R. J. Katz and H. Akil. Behiavioral effects of dynorphin-(1-13) in the mouse and rat: Initial observations. Peptides 1: 341-345. 1980.

74. Wamsley, J. K.. W. S. Young and M. J. Kuhar. Immunocytochemical localization of enkephalin in rat forebrain. Brain Res. 190: 153-174. 1980.

75. Watson, S. J. and H. Akil. Anatomy of beta-endorphin containing structures in pituitary and brain. In: Hormonal Proteins and Peptides vol. 10, edited by C. H. Li. New York: Academic Press, 1981. pp. 171-201.

76. Watson. S. J. and H. Akil. Immunocytochemistry: Techniques. trials and tribulations. Neurosci. Comment. 1: 10-15, 1981.

77. Watson. S. J., H. Akil, W. Fischli, A. Goldstein, E. Zimmerman. G. Nilaver and T. B. van Wimersma Greidanus. Dynorphin and vasopressin: Common localization in magnocellular neurons. Science 216: 85-87, 1982.
78. Watson, S. J., H. Akil, V. E. Ghazarossian and A. Goldstein, Dynorphin immunocytochemical localization in brain and peripheral nervous system: Preliminary studies. Proc. natn. Acad. Sci. U.S.A. 78: 1260-1263, 1981.

79. Watson, S. J., H. Akil, C. W. Richard and J. D. Barchas. Evidence for two separate opiate peptide neuronal systems and the coexistence of beta-lipotropin, beta-endorphin. and ACTH immunoreactivities in the same hypothalamic neurons. Nature 275: 226-228, 1978.

80. Watson, S. J., C. W. Richard and J. D. Barchas. Adrenocorticotropin in rat brain: Immunocytochemical localization in cells and axons. Science 200: 1180-1182, 1978.

81. Watson, S. J., H. Akil, S. O. Sullivan and J. D. Barchas. Immunocytochemical localization of mithionine-enkephalin: Preliminary observations. Life Sci. 25: 733-738, 1977.

82. Watson, S. J., H. Akil and J. M. Walker. Anatomical and biochemical studies of the opioid peptides and related substances in the brain. Peptides 1: Suppl. 1, 11-20, 1980.

83. Watson, S. J., J. D. Barchas and C. H. Li. Beta-lipotropin: Localization of cells and axons in rat brain by immunocytochemistry. Proc. natn. Acad. Sci. U.S.A. 74: 5155$5158,1977$.

84. Watson, S. J., H. Khachaturian, H. Akil, D. Coy and A. Golds tein. Comparison of the distribution of dynorphin systems and enkephalin systems in brain. Science, in press.

85. Weber, E.. K. A. Roth and J. D. Barchas. Colocalization of $\alpha$-neo-endorphin and dynorphin immunoreactivity in hypothalamic neurons. Biochem. biophys. Res. Commun. 103: 951-958, 1981 .

86. Weber, E., K. A. Roth and J. D. Barchas. Immunocytochemical distribution of $\alpha$-neo-endorphin/dynorphin neuronal systems in rat brain: Evidence for colocalization. Proc. natn. Acad. Sci. U.S.A. 79: 3062-3066, 1982.

87. Wuster, M., P. Rubini and R. Schulz. The preference of putative pro-enkephalins for different types of opiate receptors. Life Sci. 29: 1219-1227. 1981.

88. Wuster. M., R. Schulz and A. Herz. Opiate activity and receptor selectivity of dynorphin-(1-13) and related peptides. Neurosci. Lett. 20: 79-83, 1980.

89. Zimmerman, E. A., A. Liotta and D. T. Krieger. Betalipotropin in brain: Localization in hypothalamic neurons by immunoperoxidase technique. Cell Tissue Res. 186: 393-398, 1978. 